\title{
Solar Energy Potential in Nepal: A Meta-Analytic Review
}

\author{
Sanoj Kumar Karki \\ Department of Mechanical Engineering, Chhattisgarh Swami Vivekanand Technical University, Chhattisgarh 490001, India
}

DOI: 10.29322/IJSRP.11.05.2021.p11350

http://dx.doi.org/10.29322/IJSRP.11.05.2021.p11350

\begin{abstract}
Globally there is an energy disparity that emanates from supply shortages of clean energy that is adequate to the growing population. Clean energy is vital for poverty eradication through social-economic development in a country. Nepal has not been an exemption in an energy crisis, despite the potential for generating, 2,100 MW of solar power and 3000 MW wind power which are eco-friendly and renewable sources of energy. Nepal, as a country, is a less developed economy, with more than $80 \%$ of the population residing in rural areas. This rural population depends on nonrenewable energy sources, like traditional stoves and fuel woods, which are detrimental to the environment. Besides, fossil fuels in the country are imported, creating an economic burden on the country. Nepal has the potential to utilize solar energy as a sustainable energy source. However, this potential requires mitigation of anticipated challenges from the supply side. This research project will seek to develop recommendations for viable solar energy supply technologies by assessing and identifying possible limitations in the energy supply side; this includes analysis of solar concentrations technologies that affect the solar power output and reliability. The final report will be instrumental in developing solar thermal concentrations systems that are effective, efficient and reliable.
\end{abstract}

Index Terms- Solar energy, Photovoltaic power, Potential, Nepal

\section{INTRODUCTION}

Nepal, which is a Himalayan country, is facing the looming threat of an energy crisis. Currently, the energy demand of Nepal has partly been fulfilled by fossil fuels, Biogas, hydropower, and conventional sources of energy like fire from cow dung, wood, as well as coal [1]. The utilization of renewable energy sources is thus negligible in the region. According to Neville [2], renewable energy is the type of energy that is obtained from repetitive or continuous currents of energy that occurs in the natural environment. One of the most obvious examples of renewable energy that have proven to be dependable in a plethora of contexts is solar energy. Conventional sources of energy like the use of firewood, coal, fossil fuels, and cow dung, usually release more carbon dioxide (CO2), which is a greenhouse gas, into the atmosphere, thus leading to environmental pollution, which in turn, propels the global warming phenomenon. These prevailing problems have urged scholars and researchers to develop clean and renewable sources of energy as an alternative to fossil fuels [3]. Notably, within the context of the Nepalese region, there is a need for such sources of energy in order to attain sustainable development goals as it continues to advance in the Himalayan region.

\section{BACKGROUND}

Nepal is a considerably varied country with a complex morphology as it contains different ecosystems in an area that is relatively restricted, and this variability adds to the country's riches because the natural resources are highly diversified and spread among the regions [4]. A myriad of research has lamented over the region's utilization of nonrenewable sources of energy, which has led to unsustainable consumption of energy that may prove to be a hazard to the environment. Similarly, most of the researchers have lauded the potential of the region to utilize renewable sources of energy inclusive of hydroelectric power, as well as solar energy. In particular, researchers have pointed towards the photovoltaic power potential of the region, especially in the Kathmandu Valley, thus depicting excellent prospects for renewable energy in the area.

\section{PROBLEM STATEMENT}

Several studies have been undertaken on the solar power potential of Nepal as a country and how it can significantly enhance their energy needs using clean energy. The region has shown great potential in regards to attaining sustainable development due to excellent prospects and potential for the use of renewable energy, and in particular, solar energy. However, there is a need to review these sources of research and to ascertain if the findings of the study in regards to the potential of the region are conclusive and generalisable. Therefore, this meta-analysis has the sole purpose of reviewing previous studies and ascertaining the consistency of the results from different studies and ascertaining their dependability for the implementation of project. 


\section{METHODOLOGY}

\section{Research strategy}

Different pieces of information regarding the renewable energy have been found in order to write this paper. This paper is an existing research paper with the personal approach of the writer. Indeed numerous academic and professional cases already exist regarding the green energy.

\section{Research method}

In order to not limit the scope of the research and the nature of this one, the method of qualitative will be used in this case. There are some differences from qualitative and quantitative research.

\section{Research approach}

The inductive approach will be used in this research. In other words, general observation was used to find specific theories and conclusions. Thanks to this approach, the general context will be taken into account to understand better the subject in depth.

\section{Instruments used}

Various academic and professional cases have been used in order to understand better the subject and write the paper. Discussions with professor and experts have been conducted to help the subject understanding. A sample will be used in order to understand well the solar energy market. Different cases helped to develop the report and the analysis. However, more sources were needed as the subject is very large and need a deep understanding.

\section{POSSIBLE OUTCOMES}

Most important findings from the analysis in order to answer the two research questions are the following: The weather: Nepal's climate is very different across the country and need to be understood. Some very important: natural disaster could happen. However, the amount of sun days is ideal for the energy generation from the sun. Key players: Important companies with different market operated. Financially different. Life improvement: the solar energy will allow people to have a better life Cost: the cost of the solar energy will decrease due to higher productivity due to better understanding of the energy generation Employment: the solar power is creating employment Taxes: the government of Nepal has decided to decrease the taxes in order to encourage the investment and the development. Key component: the country still unable to manufacture high tech key components. They need the international companies to produce the energy.

\section{RESULTS}

Solar panels can convert about $18-22 \%$ of sunlight that strikes them into energy. This technology can be used in two different systems which have different efficiencies respectively which are Stand Alone Systems and Grid-tie system [6]. For our homes in Nepal, stand-alone systems will be used in which all power is stored in the battery system to keep the home powered even when the sun is not shining. With this system, homes in Nepal will be $100 \%$ solar power generated. Moreover, the use of LED's which consumes $90 \%$ less energy incandescent bulbs, the power consumption in these houses will be minimal and output maximum. Standalone systems can be converted to grid-tie systems anytime.

The future of solar power in Nepal will depend in the economy's capacity to reach the communicated target of $100 \mathrm{GW}$ of solar power energy by 2022 . Nepal is actually producing $26 \mathrm{GW}$ as of September 2018 [7]. Having been able to multiply by eight their production since 2014, they are getting closer to their target. A market with great potential is growing in the emerging country, also for foreign investors. Nepal faces however some issues in solar power energy, despite the government subsidies, the doubt in the performance and the lack of experienced banks are wary all the high-risk investment they are making. Therefore, the interest-rate on the loans are considerably high. The second factor which is slowing the progression, is the lack of competence in manufacturing solar power panels. Currently, the market players are not yet able to compete in research and development with Chinese, European or North American companies. Our research has shown that there is a wide range of businesses in the solar power industry, high potential of growth and an exponential demand for the future years.

This document does not provide a specific investment proposition, it will help getting an understanding of the solar power market in Nepal and what to expect from the government. Points to consider are clearly the increasing foreign direct investments, the licenses from the government and the lack of expertise Nepal has in the solar power technologies research [8]. The key players 19 are ahead of the average but getting some of the information was very difficult especially about companies, they are keeping those information is close to them. The methodology used for this 
report had its upsides and downside. Using case situation. However, trying to join or merge them together was complicated. I can say that focusing on a general aspect of the market is a very helpful to quickly understand more complicated aspects copy work. Being in research isn't always easy especially when it's difficult to meet in person. It however helps to understand a international business way of working. Solar power is no longer the "pipe dream of environmentalists," as much as the utility companies would like to have us believe it. While there are still two billion people in the world without access to electricity (and another billion who have it less than 10 hours per day), there are now 500,000 homes worldwide (mostly in Third World villages) powered by photovoltaic [9]. They know something the utilities don't--that power from the sun is the best power you can get.

\section{VII.CONCLUSION}

Nepal has a culture and heritage and that can be vividly seen in each and every home in different state. Modernization is also an integral part of a country's progress but not on the cost of losing its heritage and originality. This proposal is focused on a blend of both, which is modernization without losing the cultural and heritage value.The way I imagine future business opportunities of the solar market in Nepal is throw using solar power a multiple of appliances such as CCTV cameras, air conditioning units, water pumps and solar power home systems. It is not the only cities that will need electricity it is also the rural areas, and in our minds one way of doing that is through microgrid systems. I would like to do more research about rural regions and how to implement microgrid systems in order to provide green electricity to those less civilized area. Nepal has a wonderful climate for solar power energies, but I must keep in mind what would help Nepal and other developing countries use efficiently renewable energies.

\section{REFERENCES}

[1] Bajgain, S., and I. Shakya, "The Nepal Biogas Support Program." A Successful Model of Public-Private Partnership for Rural House Hold Energy, 2005. [Accessed 8 February 2020].

[2] Neville, R.C., "Solar energy conversion the solar cell", 2nd ed., Elsevier Science B.V., Amsterdam, Netherlands, 1995. [Accessed 8 February 2020].

[3] Regmi, Santosh, and Sunil Adhikary. "Solar Energy Potential in Kathmandu Valley, Nepal."Journal of Hydrology and Meteorology 8, no. 1, 2012: 77-82. [Accessed 8 February 2020]. studies were very helpful to understand the [4] Tessari, F."Renewable Energy in Nepal, ".2017, [Online]. Available: http://www.eniscuola.net/en/2007/07/01/re newable-energy-in-nepal/. [Accessed 8 February 2020]

[5] Adhikari, Krishna R., Shekhar Gurung, and Binod K. Bhattarai. "Solar energypotential in Nepal and global context." Journal of the Institute of Engineering 9, no. 1 2013: 95-106.

[6] Ale, B. B., and SO Bade Shrestha. "Hydrogen energy potential of Nepal." International journal of hydrogen energy 33, no. 15 2008: 4030-4039.

[7] Pondyal, Khem N., Binod K. Bhattarai, Balkrishna Sapkota, and Berit Kjeldstad. "Solar radiation potential at four sites of Nepal." Journal of the Institute of Engineering 8, no. 3 2011: 189197.

[8] Adhikari, Sudip, Sunil Adhikary, and Masayoshi Umeno. "PV energy potential in Nepal Himalayas: analytical study on seasonal and spatial variation of solar irradiance for PV." In 3rd World Conference onPhotovoltaic Energy Conversion, 2003. Proceedings of, vol. 2, pp. 2027-2030. IEEE, 2003.

[9] Shrestha, Ram M., and Salony Rajbhandari. "Energy and environmental implications of carbon emission reduction targets: Case of Kathmandu Valley, Nepal." Energy Policy 38, no. 9 2010: 4818-4827. 
International Journal of Scientific and Research Publications, Volume 11, Issue 5, May 2021 